\title{
Produção de cebola desidratada em Secador Solar Convectivo de Bandeja
}

\section{Dehydrated onion production in Solar Convective Tray Dryer}

\author{
Sthela Aparecida Miranda ${ }^{1}$; Kássia Graciele dos Santos ${ }^{2}$ \\ ${ }^{1}$ Aluno do Curso de Graduação em Engenharia Química, Universidade Federal do Triângulo Mineiro, \\ Uberaba, Minas Gerais, Brasil. Orcid: https://orcid.org/0000-0002-3049-9303. \\ E-mail: sthela_miranda@hotmail.com \\ 2Professora do Programa de Mestrado Profissional em Inovação Tecnológica, Universidade Federal do \\ Triângulo Mineiro, Uberaba, Minas Gerais, Brasil. Orcid: https://orcid.org/0000-0001-7452-6900. \\ E-mail: kassiagsantos@gmail.com
}

\begin{abstract}
RESUMO: Nos dias atuais, o aumento do custo da energia tem comprometido a segurança alimentar, pois implica diretamente na preparação e conservação dos alimentos. A energia solar vem destacando por representar uma das fontes não poluente e inesgotável da Terra. Nesse sentido o trabalho propõe o aperfeiçoamento de um equipamento de secagem solar, construído por estudantes de Engenharia Química da UFTM, para a secagem de cebola. Foram realizados testes laboratoriais em infravermelho e estufa a fim de determinar cinética de secagem da cebola, nas temperaturas de $60,80,100$ e $110^{\circ} \mathrm{C}$. Realizou-se também a caracterização morfológica da partícula. Duas configurações do secador solar foram testadas e comparadas, realizando testes de secagem ao sol em duas condições, alta e baixa velocidade de rotação do ventilador, monitorando a temperatura a cada 30 minutos. A cinética de secagem da cebola foi descrita satisfatoriamente pelos modelos de Page, Midili e o Logarítmo. Os resultados mostraram que a inserção do secador no interior do forno solar apresentou maior eficiência de secagem, principalmente na maior velocidade de rotação do cooler, que promove a convecção forçada. Foram alcançadas temperaturas entre $40^{\circ}$ e $60^{\circ} \mathrm{C}$, sendo que baixas razões de umidade foram obtidas quando foram utilizadas duas bandejas no secador.
\end{abstract}

Palavras-chave: modelos cinéticos, convecção, secagem, sustentabilidade.

ABSTRACT: Nowadays, the increase in the energy costs has compromised food security, which directly implies the preparation and conservation of food. Solar energy has stood out because it represents one of Earth's non-polluting and inexhaustible sources. In this sense, this work proposed the improvement of a solar drying equipment, used for onion drying. Infrared drying tests were carried out to determine drying kinetics of the onion at temperatures of $60,80,100$ and $110^{\circ} \mathrm{C}$. The particle characterization was also performed. Two configurations of the solar drying were tested and compared, performing tests of drying with high and low air velocities, recording the temperature every 30 minutes. The kinetic drying was in a good agreement with the models of Page, Midili and Logarithmic. The results showed that the insertion of the tray into the solar oven showed a higher drying efficiency, especially in the higher air velocities, which promotes forced convection. Temperatures between 40 and $60^{\circ} \mathrm{C}$ were obtained and the material reached a very low moisture ration using two trays inside the dryer.

Keywords: kinetic models, convection, drying, sustainability. 


\section{INTRODUÇÃO}

A busca por processos sustentáveis se torna cada vez mais necessária. Deseja-se suprir as necessidades atuais sem comprometer as futuras gerações e para que um empreendimento seja considerado sustentável, este deve ainda conter atitudes socialmente justas, culturalmente aceitas e economicamente viáveis.

O uso da energia solar em operações da indústria tem crescido, sendo esta usada no aquecimento de fluidos (TAVARES; SOUZA, 2019), na extração de óleos vegetais (TAVARES; SANTOS, 2016; SILVA et al., 2017; TAVARES et al., 2019), em sistemas de refrigeração por absorção e aquecimento solar (PAIVA; SOUZA, 2015), destilação solar de fluidos (SILVA et al., 2019), secagem solar (BONTEMPO et al., 2016), dentre outras operações.

O secador solar é um equipamento de simples construção e operação, não requer muitos recursos, utiliza como matéria-prima materiais alternativos acessíveis em sua construção, e a única forma de energia utilizada para o seu funcionamento é a radiação solar, o que o torna totalmente sustentável, pois esta é forma de energia limpa e renovável (VETTER, 2006). Além do mais, pode ser usado para secar vários tipos de vegetais ou frutas, bem como resíduos agroindustriais, culinários ou domésticos.

As frutas, vegetais e hortaliças constituem fontes indispensáveis de nutrientes, vitaminas e minerais, exercendo assim um importante papel na nutrição humana. Possuem um alto teor de umidade, cerca de $80 \%$, com isso se tornam altamente perecíveis, necessitando de refrigeração ou processamento o mais rápido após a colheita (GAVA; SILVA; FRIAS, 2008), a fim de diminuir as perdas. Em países de clima tropical e subtropical, essas perdas podem chegar a $40-45 \%$ da produção devido à refrigeração e armazenamento inadequados (COELHO, 2010).

Vidigal et al., 2010, afirmam que a cebola é uma das hortaliças de maior importância econômica, sendo a terceira mais cultivada no mundo, ultrapassada apenas pelo tomate e batata. No Brasil sua área de produção é de aproximadamente 70.000 ha.ano-1, com rendimento, nos últimos anos, próximo de 19 t.ha $^{-1}$,sendo que os cultivos mais bem conduzidos podem ter rendimentos entre 40 e 60 t.ha $^{-1}$ ou até mesmo superior.

Em sua composição, a cebola contém alguns compostos bioativos, como organosulfurados e flavonoides, bem como inúmeros outros compostos, como o selênio, que age contra o câncer, vitaminas do complexo B, que atuam na formação de anticorpos, dando resistência ao corpo contra infecções e reduzindo níveis de colesterol ruim, vitamina $\mathrm{C}$, antioxidantes, vitamina $\mathrm{A}$, betacaroteno, que combate os radicais livres, aumenta a imunidade e estimula o metabolismo do organismo. A cebola contém ainda em sua composição nutricional ferro, cálcio, fósforo, iodo, magnésio, zinco, potássio, sódio e flúor, minerais que equilibram os fluidos e leva oxigênio para a estrutura muscular, permitindo a regulação energética do corpo (MUNIZ, 2007).

A cebola é consumida principalmente in natura na forma de saladas, condimento ou tempero na alimentação humana. Porém, apresenta cerca de 86 a $92 \%$ de água, o que a torna uma hortaliça altamente perecível. Isso proporciona altas perdas pós colheita e limita seu período de comercialização. Grande parte da sua produção tem sido comercializada nas formas cozida, picles congelados, desidratados (pó e flocos), essência (óleo de cebola), bulbos enlatados (conserva), e desidratada a frio (BOEING, 2002).

Por apresentar alta umidade, é passível o crescimento de microrganismos que podem acarretar na degradação do material. A atividade de água é uma das medidas mais comuns empregadas para expressar a água disponível em alimentos. Uma redução na 
atividade de água pode limitar a água disponível e diminuir a proliferação dos microrganismos, conservando os alimentos (LEVANDOWSKY, 1981).

Uma das técnicas mais antigas na conservação de alimentos é a desidratação, que consiste na eliminação de água de um produto por evaporação, devido à transferência de calor e massa. Os alimentos podem ser desidratados por diferentes métodos, e no Brasil é comum realizar a desidratação em secadores do tipo cabine com bandejas e circulação forçada de ar quente.

A secagem constitui em uma operação unitária muito importante na conservação de alimentos, pois tem como finalidade reduzir a atividade da água, reações enzimáticas do produto, além de aumentar o tempo de prateleira.

Essa operação possibilita o contato direto do material com o ar insaturado e aquecido resultando na redução do conteúdo de umidade do material e na umidificação do ar (INCROPERA; DEWITT, 2008). Durante a operação de secagem, ocorrem dois processos simultâneos no material, a transferência de calor do meio circundante, resultando na evaporação do líquido contido no material e a transferência de massa na forma de líquido ou vapor do interior do material para a superfície, e desta para a corrente em escoamento do ar de secagem (BORTOLOTTI et al., 2013).

Segundo Coelho (2010), os legumes e as hortaliças desidratados apresentam como principais vantagens: não necessitarem de refrigeração durante 0 transporte ou armazenamento, serem compatíveis com outros ingredientes nas misturas desidratadas, como sopas, e a grande redução de massa e volume. Assim, a secagem pode significar considerável economia no transporte, no manuseio e na estocagem do produto, além de significar um efetivo método de prolongamento de sua vida útil, já que diminui a ação microbiana. Assim, o interesse por alimentos desidratados tem crescido paralelamente ao aumento da demanda por alimentos de consumo imediato.

A carência de energia nos dias atuais compromete a segurança alimentar, já que tem implicações diretas na preparação e conservação dos alimentos, entre outras funções básicas diárias. Nesse sentido o sol se mostra como uma fonte de energia alternativa, pois constitui uma energia sustentável, autossuficiente, que não causa danos ao meio ambiente, além de ser inesgotável é gratuita e pode ser usada de diversas formas em benefício das pessoas (IEHT,2009).

A secagem dos alimentos por meio da energia solar é uma técnica antiga de conservação dos alimentos de baixo custo e muito simples, e pode ser realizada em secadores solares, que podem ser de dois tipos: secador de exposição direta e secador de exposição indireta, podendo haver convecção natural ou forçada.

A secagem indireta apresenta vantagens sobre a secagem direta, pois quando os alimentos são expostos diretamente à radiação solar ficam sujeitos a contaminação, além da diminuição das propriedades nutricionais, o que provoca grandes perdas de produto e reduz a sua qualidade final. Esse tipo de tecnologia é ideal para ser aplicada em países tropicais como o Brasil, que dispõe de longos períodos do ano com pouca nebulosidade, baixa umidade relativa do ar e elevada incidência de radiação solar (BONTEMPO et al., 2016).

Fornos solares são fornos sustentáveis geralmente utilizados para cozinhar alimentos, frequentemente usados em locais que possuem uma alta incidência solar durante o dia, ou em locais em que a condição socioeconômica da população não é suficiente para conseguirem adquirir fornos à base de gás natural ou lenha (GUIA DA ENERGIA SOLAR, 2013). 
São vantagens de um forno solar: a fácil construção e os materiais utilizados são baratos; não ser necessária nenhuma outra forma de energia, que não a radiação solar; eles podem ser construídos em diversas escalas; não há necessidade da presença do usuário (PLENO SOL COZIMENTO SOLAR, 2012; MELO, 2008).

A secagem da cebola trata-se de uma atividade agroindustrial para a maior conservação da matéria-prima e, sobretudo para o aproveitamento da fração classificada como fora do padrão de comercialização. Inúmeras formulações de produtos, como os d instantâneo, por exemplo, utilizam a cebola desidratada como ingrediente, sendo que esta também se apresenta para o consumidor como condimento de mesa (MARTINS; PINTO, 2003).

Neste contexto, o objetivo deste trabalho foi estudar a secagem com radiação solar da cebola, em um secador convectivo do tipo bandeja. Duas configurações do equipamento foram avaliadas, bem como o efeito do aumento da velocidade do ar sobre a taxa de secagem. Na Configuração A, o secador foi posicionado após o forno solar do tipo caixa, que aquecia o ar, sendo usada uma bandeja dentro do secador. Já na Configuração B, o secador foi inserido dentro do forno solar e era constituído de um duto metálico de secção retangular, dentro do qual o ar de secagem escoava e onde as partículas eram colocadas. A cinética de secagem e as características das partículas (forma, tamanho, densidade) também foram efetuadas.

\section{MATERIAL E MÉTODOS}

\section{Caracterização do material particulado}

As cebolas utilizadas na desidratação foram do cultivar Pera. Elas foram lavadas em água corrente, descascadas, e cortadas em paralelepípedos.

Para a análise da forma das partículas de cebola, foi calculada a esfericidade, como sendo a relação entre a área superficial da esfera de mesmo volume que a partícula, e a área superficial da partícula. Para tal, separou-se uma amostra do material e as dimensões das partículas foram quantificadas com um paquímetro.

A partir dessas mesmas medidas, foi obtido o diâmetro volumétrico de cada partícula da amostra, que é o diâmetro da esfera que tem o mesmo volume que a partícula. Com esses diâmetros, foram testados os diferentes Modelos de Distribuição Granulométrica, dentre eles os modelos GGS, RRB e Sigmóide.

A densidade aparente das partículas foi obtida pela razão entre a massa e o volume de uma outra partícula de cebola, de tamanho conhecido $(1,92 \times 1,9 \times 1,4 \mathrm{~cm})$, em triplicata.

\section{Unidades Experimentais}

\section{Configuração A:}

A Figura 1a apresenta a Configuração A do secador solar, que é composto por: 1) o forno solar, onde o ar é aquecido; 2) câmara de secagem que contém as partículas; 3) o coletor solar. $O$ forno solar possui dimensões de $1,5 \times 0,3 \times 0,3 \mathrm{~m}$ e foi construído com madeira MDF, revestido com papel alumínio e o seu fundo recoberto com placas de metal.

$\mathrm{O}$ secador foi construído com um tubo de PVC com $20 \mathrm{~cm}$ de diâmetro. O coletor solar foi construído com retalhos de espelhos e possui uma angulação de $60^{\circ}$. A admissão de ar para dentro do forno é feita através de um ventilador Marca Adda ( $6 \mathrm{~W}, 12 \mathrm{v}, 500 \mathrm{~mA})$, que promoveu a convecção forçada do ar de secagem. 


\section{Configuração B}

$\mathrm{Na}$ Configuração B do secador, o tubo de PVC que abrigava a bandeja foi substituído por uma calha de aço galvanizado, disposta no interior do forno, como mostra a Figura 1b. A calha possui dimensões de $1,45 \mathrm{~m} \times 10 \mathrm{~cm} \times 7,5 \mathrm{~cm}$, foi devidamente higienizada e esterilizada com solução alcoólica $70 \%$ (v/v) e posteriormente pintada com tinta spray preta a fim de conservar o calor no secador por mais tempo.

\section{Experimentos de Secagem Solar}

Para realização dos experimentos usou-se sempre uma massa fixa de aproximadamente $150 \mathrm{~g}$ de cebola cortada em cubos. O equipamento foi sempre posicionado onde havia maior incidência de raios solares, e ao colocar o material a ser seco dentro do mesmo tomou-se as medidas de temperatura de 30 em 30 minutos por meio de um termômetro de mercúrio.

Figura 1. Secador solar convectivo do tipo bandeja: (a) Configuração A; (b) Configuração B.

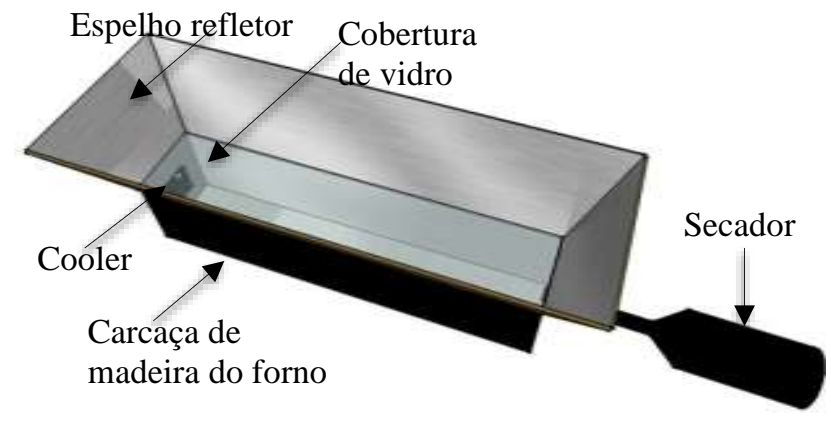

(a)

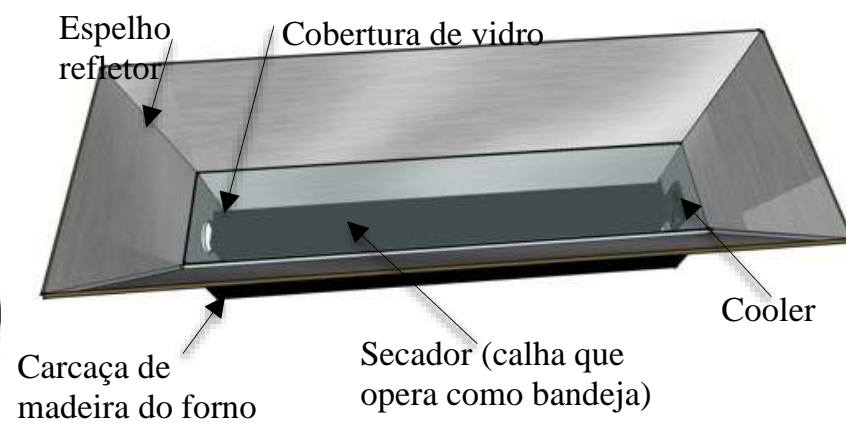

(b)

A fim de conduzir os testes de secagem empregando energia solar nas duas configurações de secador apresentadas, foi proposto um planejamento fatorial $2^{2}$, com duas variáveis qualitativas e dois níveis. O planejamento busca avaliar o efeito do tipo de configuração do secador e da rotação do ventilador, sobre a eficiência de secagem, que pode ser avaliada pela razão de umidade do material produzido.

\section{Cinética de secagem}

Foram realizados testes de laboratório em um analisador de umidade infravermelho (marca GEHAKA, modelo IV 2500), para a obtenção do melhor modelo que representa a cinética de secagem da cebola, bem como a difusividade média efetiva do material. $O$ equipamento também conta com uma balança que permite a leitura direta da porcentagem de umidade perdida.

Os testes de cinética de secagem foram realizados nas temperaturas de $60,80,100$ e $110^{\circ} \mathrm{C}$. A porcentagem de umidade perdida foi registrada inicialmente de $30 \mathrm{em} 30$ segundos, após de 1 em 1 minuto e posteriormente de 5 em 5 minutos até que a umidade da cebola atingisse o equilíbrio.

Para a determinação da razão de umidade, fez-se uso da seguinte relação: 


$$
R U_{i}=\frac{X_{b s i}-X_{e}}{X_{b s 0}-X_{e}}
$$

Em que $X_{b s i}$ é a umidade em base seca no instante (i), $X_{e}$ é a umidade de equilíbrio e $X_{b s 0}$ é a umidade em base seca inicial (massa de água (g) por massa de material seco (g)). Para determinação da umidade inicial e residual da cebola foram realizados testes em estufa, a $105^{\circ} \mathrm{C}$, por $24 \mathrm{~h}$.

$\mathrm{Na}$ análise dos dados, foi adotada a hipótese de equilíbrio dinâmico, ou seja, no final do experimento, quando não mais se registra a perda de umidade da amostra, considerase que a umidade residual está próxima à umidade de equilíbrio. Para o cálculo da taxa de secagem, $\left(\mathrm{Kg}\right.$ água. $\mathrm{Kg}^{-1}$ sólido. $\left.\mathrm{s}^{-1}\right)$ utilizou-se a equação 2 :

$$
N=\frac{\Delta R U}{\Delta t}
$$

Em que $\Delta R U$ corresponde a variação da razão de umidade em cada instante (Kg água . $\mathrm{Kg}^{-1}$ sólido) e $\Delta t$ é a variação do tempo (s).

A partir dos dados de perda de massa das amostras durante a secagem nas diferentes temperaturas, foram testados algumas das equações que descrevem a cinética de secagem mais empregados na literatura, que estão disponíveis na Tabela 1 (COELHO, 2010; SOUZA, 2013). Os parâmetros cinéticos de cada modelo foram calculados, sendo escolhido o modelo que apresentou maior coeficiente de correlação quadrático.

Tabela 1. Equações empíricas para ajuste de curvas de secagem.

\begin{tabular}{lll}
\hline Modelo & Equação, considerando $K(T)=a \exp (-b / T f)$ & \\
\hline Lewis (1921) & $R U=\exp [(-K t)]$ & $(3)$ \\
Brooker, et. al (1974) & $R U=c \exp [(-K t)]$ & $(4)$ \\
Henderson e Henderson (1968) & $R U=c \exp [(-K t)+1 / 9 \exp (-9 K t)]$ & $(5)$ \\
Page (1949) & $R U=\exp \left[\left(-K t^{n}\right)\right]$ & $(6)$ \\
Midili & $R U=c \exp (-1(a \exp (-b / T)) K n)+d K$ & $(7)$ \\
Logarítmico & $R U=c \exp (-1(a \exp (-b / T)) K n)+d$ & $(8)$ \\
\hline
\end{tabular}

Fonte: Souza (2013)

O parâmetro $\mathrm{K}(\mathrm{T})$, apresentado nestas equações da Tabela 1, é conhecido como constante da taxa de secagem, que expressa a velocidade com que a secagem ocorre. Este termo, oriundo da equação que melhor representa a taxa de secagem experimental, será empregado para determinar uma equação para a difusividade mássica efetiva $\left(D_{e f}(T)\right)$, em função da temperatura (T [K]), segundo a Equação 9 (MARTINS; PINTO, 2003), na qual $L_{0}$ é a metade da espessura da partícula $(\mathrm{cm})$.

$$
D_{e f}(T)=\left(L_{0} / \pi\right)^{2} \cdot K(T)
$$




\section{RESULTADOS E DISCUSSÕES}

\section{Caracterização das partículas}

As partículas empregadas nos testes de secagem apresentaram uma densidade aparente de $0,975 \mathrm{~g} / \mathrm{cm}^{3}$. A análise morfológica das partículas é importante, uma vez que com informações sobre o tamanho e forma das partículas é possível inferir sobre o encolhimento do material após a secagem. Além disso, o tamanho das partículas é empregado na definição da difusividade efetiva de secagem (Eq. 9), fornecendo o parâmetro Lo. O valor da esfericidade obtida foi de 0,71 . O modelo que melhor representou a distribuição de tamanho das partículas foi o Modelo Sigmóide $\left(R^{2}=0,978\right)$, definido pela equação 10 , sendo que os parâmetros do modelo encontrados foram: $d_{50}=0,602 \mathrm{~cm}$ e $p=15,68$.

$$
X=1 /\left[1+\left(d_{50} / d_{v}\right)^{p}\right]
$$

\section{Cinética de secagem}

Estudou-se a cinética de secagem analisando-se a influência da temperatura na cinética de secagem da cebola. As curvas de secagem estão apresentadas na forma de razão de umidade em função do tempo e são mostradas na Figura 2a. Observa-se que a perda do teor de umidade é mais rápida no início do processo de secagem, pois há mais água livre na superfície para ser retirada. Percebe-se ainda, que a cinética de secagem foi fortemente influenciada pela temperatura, isto é, a secagem a uma temperatura mais elevada reduz expressivamente o tempo necessário para secar a cebola.

Analisando a curva da taxa de secagem em função da umidade em base seca para a temperatura de $60{ }^{\circ} \mathrm{C}$ (Figura 2b), pode-se observar a ocorrência de três períodos distintos da secagem, observador da direita pra esquerda: (1) indução (no início do experimento a umidade é alta); (2) taxa constante; (1) taxa decrescente.

Figura 2. Curvas de secagem da cebola. (a) Razão de Umidade em função do tempo de secagem, para as temperaturas de $60,80,100$ e $110^{\circ} \mathrm{C}$; (b) Taxa de secagem (à $60^{\circ} \mathrm{C}$ ) em função da umidade em base seca.
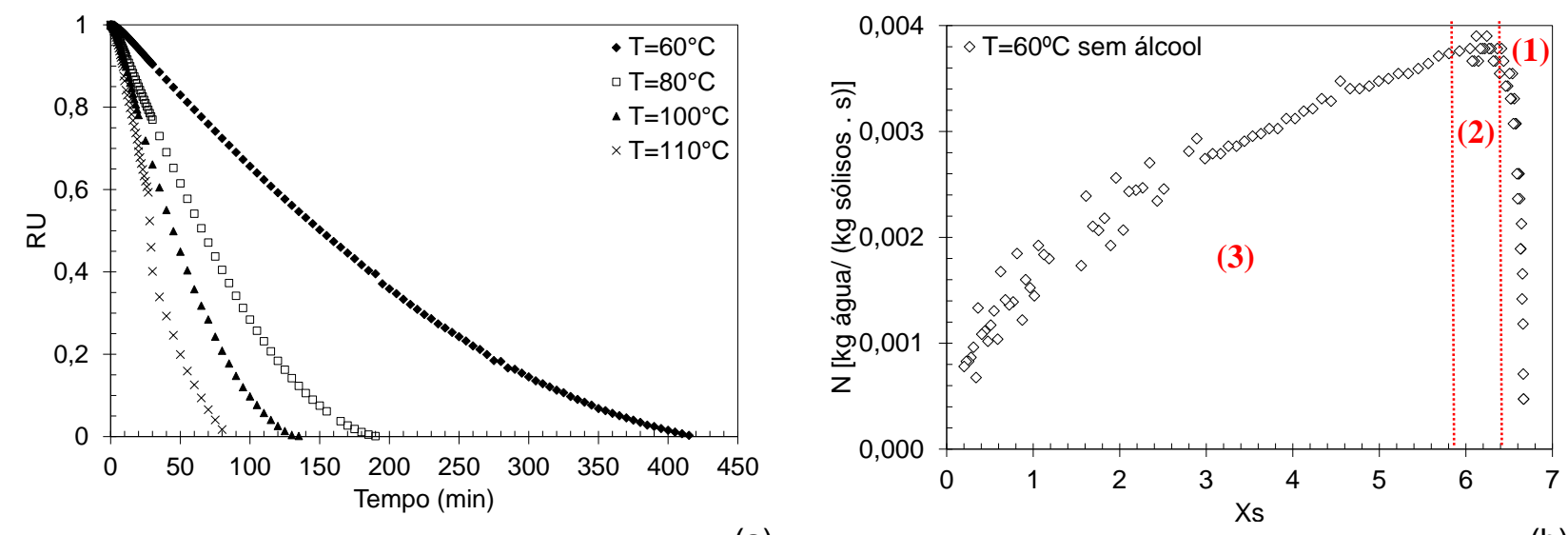

(a) 
Os parâmetros dos ajustes das curvas de secagem empregando as equações empíricas da literatura são mostrados na Tabela 2. Nota-se que o modelo que melhor ajustou os dados experimentais de perda de umidade da cebola foi o Modelo Logarítmico, pois este apresentou o melhor coeficiente de correlação quadrática $\left(R^{2}=0,993\right)$.

Para o cálculo da difusividade efetiva utilizou-se a Equação 9 (MARTINS; PINTO, 2003), considerando $L_{0}$ como a metade da espessura do sólido $(\mathrm{cm})$, que no caso da cebola foi cerca de $0,12 \mathrm{~cm}$. Usando o modelo Logarítmico, que foi o que melhor ajustou os dados experimentais, obteve-se $D_{e f}\left(\mathrm{~cm}^{2} / \mathrm{s}\right)$ em função da temperatura $(\mathrm{K})$, como mostra a Equação 11, em que o parâmetro cinético " $a$ " tem unidade de $\mathrm{s}^{-1}$.

$$
D_{e f}=3,578 \exp \left(\frac{-4635,47}{T}\right)
$$

Tabela 2. Parâmetros cinéticos encontrados para os Modelos da Tabela 1.

\begin{tabular}{|c|c|c|c|c|c|}
\hline Modelo & Parâmetros & $\mathrm{R}^{2}$ & Modelo & Parâmetros & $\mathrm{R}^{2}$ \\
\hline I ewis & $a=162,293$ & 0969 & \multirow[b]{3}{*}{ Midilli } & $C=0,991$ & \multirow[b]{3}{*}{0,992} \\
\hline & $b=3419,943$ & & & $a=3860,375$ & \\
\hline Henderson & $\begin{array}{l}c=0,995 \\
a=161,470 \\
b=3413,900\end{array}$ & 0,967 & & $\begin{array}{l}b=5165,072 \\
n=1,382 \\
d=0,000\end{array}$ & \\
\hline Brooker & $\begin{array}{l}c=1,062 \\
a=210,850 \\
b=3481,511\end{array}$ & 0,978 & \multirow[b]{2}{*}{ Logarítmico } & \multirow{2}{*}{$\begin{array}{l}c=1,083 \\
a=1221,765 \\
b=4635,470 \\
n=1,280 \\
d=-0,085\end{array}$} & \multirow[b]{2}{*}{0,993} \\
\hline Page & $\begin{array}{l}a=2785,128 \\
b=5024,969 \\
n=1,378\end{array}$ & 0,992 & & & \\
\hline
\end{tabular}

\section{Secagem Convectiva com Energia Solar}

Nesta etapa, foram realizados inicialmente 4 experimentos definidos pelo planejamento fatorial $2^{2}$. No qual se buscou avaliar o efeito da configuração do secador (Configurações $\mathrm{A}$ e B) e da rotação do ventilador (maior e menor), sobre a razão de umidade final obtida, bem como a umidade residual em base seca.

Os resultados obtidos estão disponíveis na Tabela 3. Pode-se observar que os testes realizados na configuração $A$ (Experimentos 1 e 2) apresentaram umidade residual muito elevada, frente aos valores obtidos pela Configuração B. A Figura 3 mostra o aspecto da cebola seca em cada experimento do planejamento fatorial, onde observa-se que a desidratação foi bem mais efetiva na Configuração B. 
Tabela 3. Dados experimentais para as diferentes condições avaliadas.

\begin{tabular}{|c|c|c|c|c|}
\hline \multirow[b]{2}{*}{ Experimento } & \multicolumn{2}{|c|}{ Variáveis (codificação) } & \multicolumn{2}{|c|}{ Respostas } \\
\hline & $\begin{array}{l}\text { Configuração do } \\
\text { Equipamento } \\
\left(x_{1}\right)\end{array}$ & $\begin{array}{l}\text { Rotação } \\
\text { (x2) }\end{array}$ & $\begin{array}{c}\text { Xs } \\
{\left[\frac{\mathrm{kg} \text { de água }}{\mathrm{kg} \text { de sólido }}\right]}\end{array}$ & $R U$ \\
\hline 1 & $A(-1)$ & Baixa $(-1)$ & 5,13 & 0,4740 \\
\hline 2 & $A(-1)$ & Alta $(+1)$ & 3,72 & 0,3280 \\
\hline 3 & $B(+1)$ & Baixa $(-1)$ & 0,30 & 0,0130 \\
\hline 4 & $\mathrm{~B}(+1)$ & Alta $(+1)$ & 0,23 & 0,0045 \\
\hline 5 & A & Baixa com 2 bandejas & 1,28 & 0,0932 \\
\hline
\end{tabular}

Figura 3. Aspecto final da cebola após a secagem: (a) Exp. 1; (b) Exp. 2; (c) Exp. 3; (d) Exp. 4.

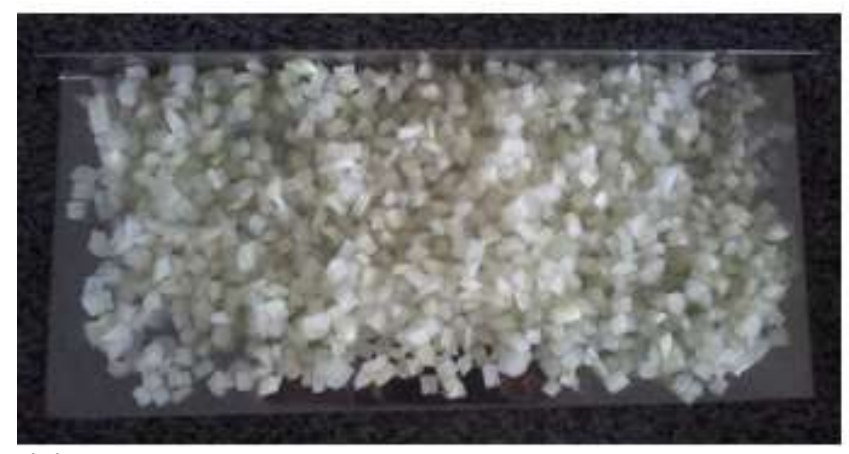

(a) Experimento 1

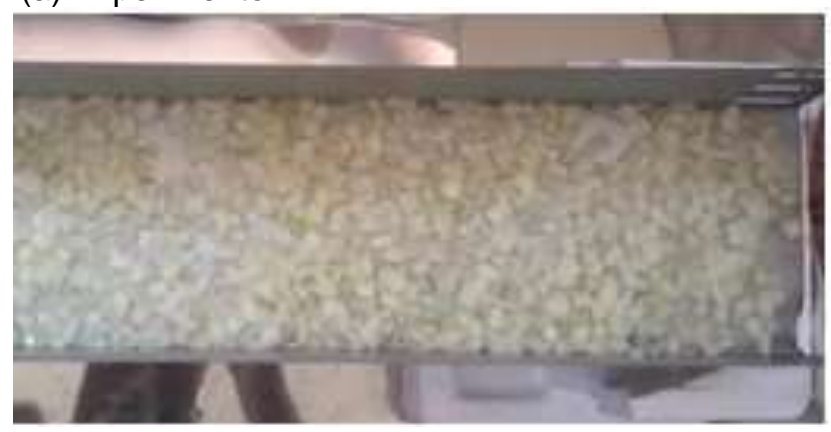

(c) Experimento 3

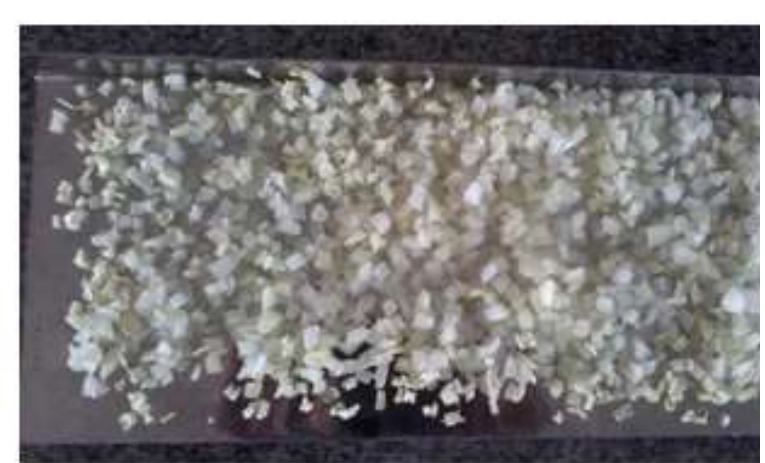

(b) Experimento 2

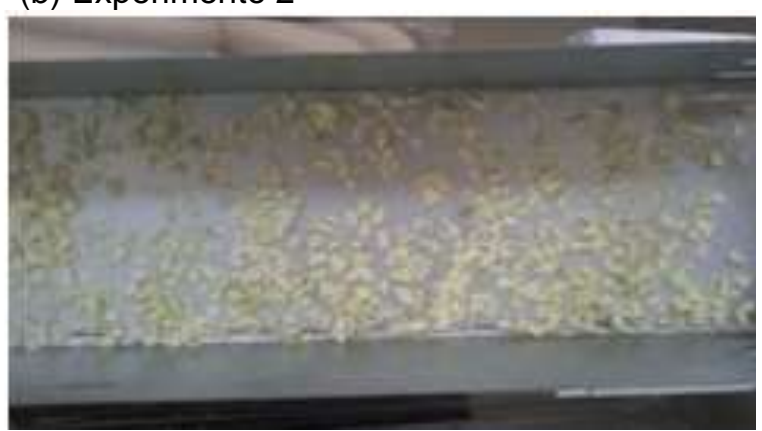

(d) Experimento 4

As variações de temperatura com o transcorrer do tempo para cada experimento são mostradas na Figura 4. Vale ressaltar que a temperatura do ar secagem é dependente das condições climáticas, não sendo possível controlar seu valor neste tipo de experimento. No entanto, todos os experimentos foram realizados em dias ensolarados, com poucas nuvens. 
Figura 4. Gráfico com as variações de temperatura com o passar do tempo nas diferentes condições experimentais (todos os dias foram ensolarados, com poucas nuvens).

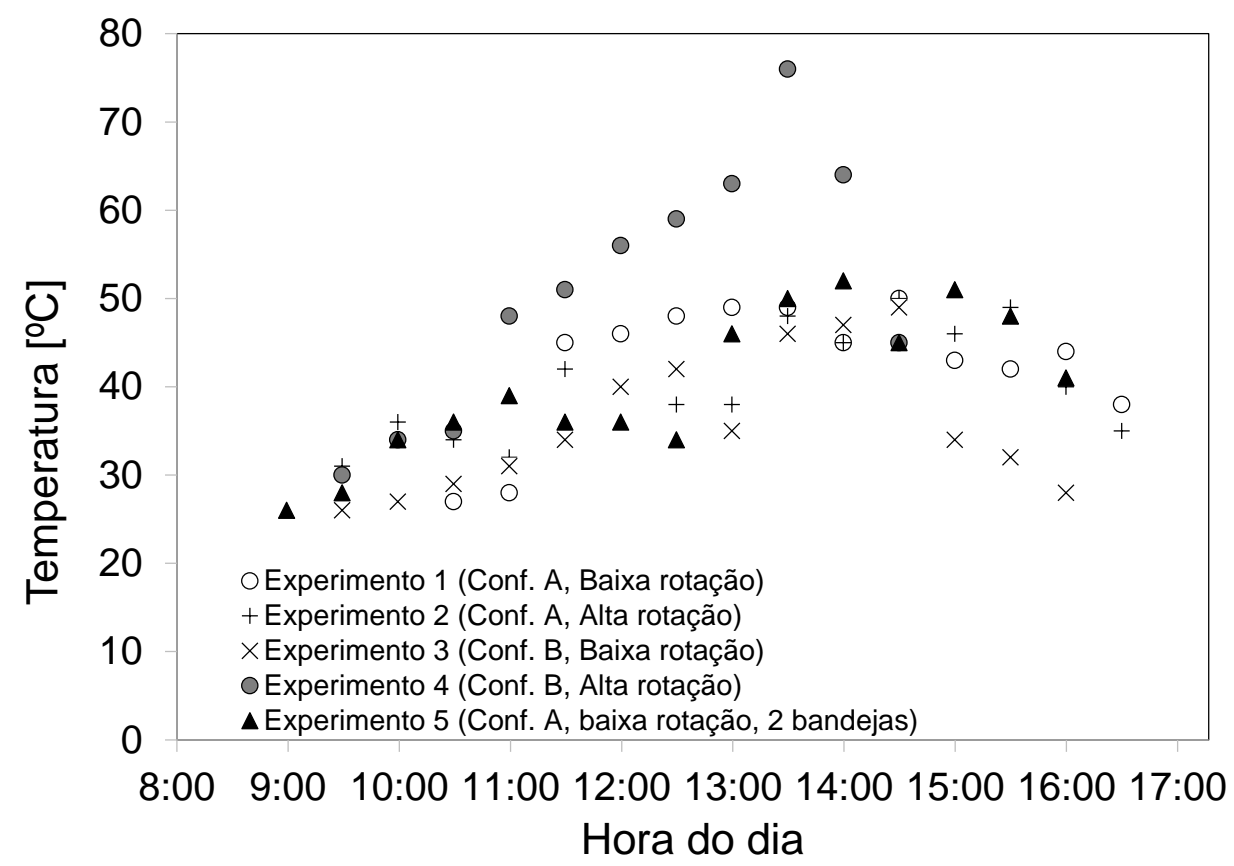

Nota-se ainda que nem todos os experimentos começaram no mesmo horário e tiveram a mesma duração, o que também se deu devido as condições climáticas. O ideal seria repetir os experimentos nas mesmas condições e duração. Porém, pelo fato dos testes terem sido realizados no verão, que é uma época que possui grande incidência solar, e ao mesmo tempo altas precipitações, se torna mais difícil a realização de muitos experimentos e nas mesmas condições.

A fim de avaliar o efeito das variáveis estudadas sobre a umidade final da cebola, optou-se pela metodologia estatística utilizando a técnica de superfície de resposta. Foi realizada uma análise de múltipla regressão, sendo os parâmetros estimados por mínimos quadrados, com um nível de significância do teste de $10 \%$. A análise de variância da regressão foi apresentada através do teste de $F$ e do coeficiente de correlação $R^{2}$.

A Tabela 4 representa os resultados da regressão para a razão de umidade removida durante a secagem. Observa-se que o tipo de secador é que exerce o maior efeito sobre a razão de umidade. O sinal negativo do coeficiente mostra que no maior nível da variável 1 (Configuração $B$ ) é que se atinge os menores valores de $R U$ ao fim do experimento. Avaliando a razão de umidade no fim dos experimentos (Tabela 3), observase que independentemente do tipo do secador, a alta rotação do cooler produziu menores $\mathrm{RU}$ residuais, mas esse efeito não chega a ser estatisticamente significativo, devido ao elevado nível de significância $(p=0,4619)$. Acredita-se que a faixa de velocidades geradas pela menor e maior rotação do cooler não modificaram significativamente a transferência de calor e massa por convecção durante a secagem. As mesmas conclusões podem ser obtidas através da análise da superfície de resposta para a razão de umidade (RU), disposta na Figura 5. 
Tabela 4. Efeitos das variáveis sobre a razão de umidade residual ao fim da secagem $\left(R^{2}=0,973\right)$.

\begin{tabular}{lccc}
\hline Fator & Parâmetro & Desvio & Nível de Significância \\
\hline Média & 0,2037 & 0,0335 & 0,1033 \\
$x_{1}$ & $-0,1949$ & 0,0333 & 0,1079 \\
$x_{2}$ & $-0,0376$ & 0,0333 & 0,4619 \\
$x_{1} x_{2}$ & 0,0333 & - & $>0,4600$ \\
\hline
\end{tabular}

Figura 5. Superfície de resposta para a razão de umidade em função do tipo de secador e rotação do cooler (variáveis codificadas).

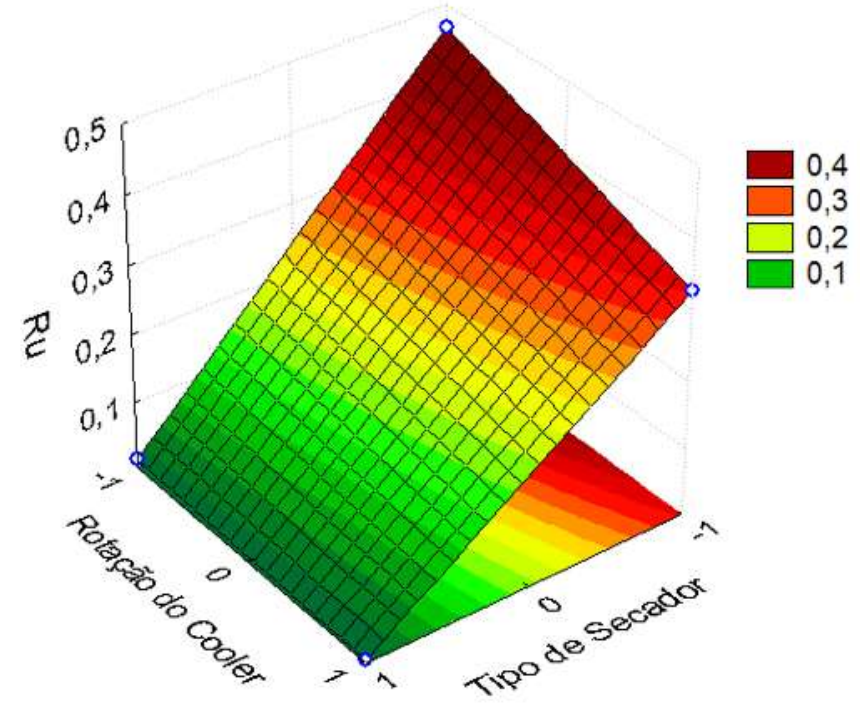

No momento da realização dos experimentos com a configuração original (A), percebeu-se que usando apenas uma bandeja formava-se uma camada muito espessa de cebola, o que pode ter dificultado a passagem do ar sobre o material, influenciando negativamente na eficiência de secagem do mesmo. A fim de verificar essa hipótese realizou-se um novo experimento, com baixa velocidade de rotação do cooler e duas bandejas, denominado Exp. 5, com resultado disponível na Tabela 3.

Ao comparar os Experimentos 1 e 5 (com 2 bandejas), nota-se uma melhora na eficiência de secagem, que pode ser atribuída a melhor distribuição do material sobre as bandejas. No entanto, a secagem realizada no secador com configuração B ainda se mostrou mais eficiente. Esse resultado encontrado na Configuração $B$ do equipamento pode ser explicado pela introdução da calha e das placas de metal no interior do forno. A calha é feita de aço galvanizado que é um bom condutor de calor, com isso a calha preta funciona como corpo absorvedor da radiação solar, e transfere calor para o ar, o que possibilita atingir maiores temperaturas. Além disso, a câmara de secagem (calha) está dentro do forno solar, reduzindo as perdas de calor para o ambiente, que ocorrem na Configuração A quando o ar escoa do forno para a câmara de secagem.

De modo geral pode-se dizer que as alterações feitas no equipamento de secagem, proporcionaram significativa melhoria na eficiência de remoção da umidade do material. A cebola seca apresentou visualmente as características desejadas, com um aspecto folheado. 
Barbosa (2011) realizou a secagem solar não convectiva de cerca de $318 \mathrm{~g}$ de cebola, em um secador solar com exposição direta ao sol. Foram necessárias cerca de 16 $\mathrm{h}$ para que o material perdesse cerca de $85 \%$ da massa inicial, o que corresponde a um $X \mathrm{~s}=0,5$ ( $\mathrm{kg}$ água/ $\mathrm{kg}$ sólido seco). Neste trabalho, a cebola seca na Configuração $B$ apresentou um desempenho semelhante, porém mais eficiente, uma vez que realizou a mesma secagem em apenas $6 \mathrm{~h}$. Além disso, a cebola do presente trabalho apresentou baixo escurecimento por não ter sido diretamente exposta à luz solar.

Do ponto de vista da relevância econômica e social e do desenvolvimento regional, os equipamentos para secagem solar convectiva propostos são sustentáveis ambientalmente, economicamente viáveis e de fácil operação e construção, constituindo assim uma excelente alternativa para pequenas e médias propriedades rurais da região. Desta forma, unidades otimizadas desses equipamentos poderiam ser instaladas em pequenas e médias propriedades agrícolas e cooperativas, que com treinamento adequado, poderiam ser operadas sem grandes dificuldades.

\section{CONCLUSÕES}

Pela análise das curvas de secagem pode-se perceber que a temperatura influência significativamente na taxa de secagem, ou seja, quanto maior a temperatura menor é o tempo gasto para a desidratação da cebola.

Quanto à melhor configuração do equipamento, pode-se afirmar que o secador do tipo $B$ foi mais eficiente, já em todas as condições apresentou melhores resultados em relação à umidade final da cebola e as maiores temperaturas foram atingidas nesse equipamento.

No entanto, os níveis de rotação do cooler avaliados não alteraram significativamente a taxa de secagem, quando avaliado em conjunto com o tipo de configuração.

\section{NOMENCLATURA}

$a, b, c, d, n$ : Parâmetros dos Modelos cinéticos de secagem

$D_{e f}: \quad$ Difusividade Efetiva em função da temperatura $\left[\mathrm{cm}^{2} \cdot \mathrm{s}^{-1}\right]$

$d_{v}$ : $\quad$ Diâmetro da esfera de igual volume que a partícula [mm]

$d_{50}$ : Parâmetro do Modelo Sigmóide; Diâmetro em que 50\% das partículas da amostra são inferiores a ele [mm]

$K(T)$ : Constante de secagem em função da temperatura

$L_{0}$ : $\quad$ Metade da espessura da partícula [cm]

$N: \quad$ Taxa de secagem [kg água. $\mathrm{kg}^{-1}$ sólido. $\left.\mathrm{s}^{-1}\right]$

p: $\quad$ Parâmetro do Modelo Sigmóide

RU: $\quad$ Razão de Umidade

$t: \quad$ Tempo

$T: \quad$ Temperatura

$X: \quad \quad \quad \quad$ Fração mássica acumulativa

$X_{b s i}: \quad \quad$ Umidade em base seca no instante (i).

$X_{e}$ : $\quad$ Umidade de equilíbrio dinâmico

$X_{b s 0}: \quad$ Umidade em base seca inicial

$x_{1} ; x_{2}: \quad$ Variáveis codificadas 


\section{AGRADECIMENTOS}

Os autores agradecem à UFTM pela Bolsa de Auxílio à Permanência (PROACE) e ao $\mathrm{CNPq}$ pela Bolsa PIBIC de Iniciação Científica e à Capes pelo Auxílio à Pesquisa (AUXPE0856/2015).

\section{REFERÊNCIAS}

BOEING, G. Fatores que afetam a qualidade da cebola na agricultura familiar catarinense. Florianópolis: Instituto Cepa/SC, 2002. 80p.

BONTEMPO; L. H. S; SILVA, R. N., CARDOSO, V. S., CASTEJON, L. V, SANTOS, K. G., Avaliação da farinha de fruta obtida por meio da secagem solar convectiva de cascas de mexerica. In: Anais do Congresso Brasileiro de Engenharia Química, Fortaleza, 2016.

BORTOLOTTI, C. T.; SANTOS, K. G.; FRANCISQUETTI, M. C. C.; DUARTE, C. R.; BARROZO, M. A. S. Hydrodynamic study of a mixture of West Indian Cherry Residue and Soybean Grains in a spouted bed. Canadian Journal of Chemical Engineering, v. 91, p. 1871-1880, 2013.

COELHO, K. D. Secagem de tomate (Lnycorpesicon esculentummill) em camada delgada: avaliação das características físico-químicas. 2010. 97 p. Dissertação (Mestrado em Engenharia de Alimentos) - Universidade Federal do Rio Grande, Rio Grande, 2010.

GAVA, A. J., SILVA, C. A. B.; FRIAS, J. R. G. Tecnologia de alimentos: princípios e aplicações. São Paulo: Nobel, 2008, 512 p.

GUIA DA ENERGIA SOLAR. Concurso solar Padre Himalaya. Disponível em: https://img.circuitoscienciaviva.pt/img/recursos/files/guia2_10196429785c1a.pdf. Acesso em: 19 nov. 2014.

IEHT. Instituto de Estudios del Hambre. Tecnologias. Sociais para a Segurança Alimentar, 2009.

INCROPERA, F. P.; DEWITT, D. P. Fundamentos de Transferência de Calor e Massa. 6. ed. Rio de Janeiro: LTC, 2008.

LEVANDOWSKY, M. Microbial Ecology of Foods. Volume 1: Factors Affecting Life and Death of Microorganisms. The International Commission on Microbiogical Specifications for Foods. The Quarterly Review of Biology, v. 56, n. 2, p. 204-204, 1981.

MARTINS, P. C; PINTO, L. A. A. Caracterização da Secagem de Cebola (Allium cepa L.) em Camada Delgada e da Reidratação do Produto Desidratado. Brazilian Journal of Food Technology, v.6, p.143-151, 2003.

MELO, A. V. Projeto, construção e análise de desempenho de um forno solar alternativo tipo caixa a baixo custo. 2008. 85 f. Dissertação (Mestrado em Tecnologia 
de Materiais; Projetos Mecânicos; Termociências) - Universidade Federal do Rio Grande do Norte, Natal, 2008.

MUNIZ, L. B. Caracterização química, física e de compostos funcionais em cebolas frescas e minimamente processadas. 2007. 160 p. Dissertação (Mestrado em Nutrição Humana) - Universidade de Brasília, Brasília, 2007.

PAIVA, L. S.; SOUSA, N. G. Simulação e análise de um sistema de refrigeração por absorção e aquecimento solar. Revista Brasileira de Ciência, Tecnologia e Inovação, v. 1, n. 2, p. 25-42, 2015.

PLENO SOL COZIMENTO SOLAR. Manual do proprietário: Forno solar P.S. Multiuso. 2012. Disponível em: http://plenosol.wordpress.com. Acesso em 29 nov. 2014.

SILVA, L. R. C.; RIBEIRO, M. B. M.; OLIVEIRA, A. D.; SANTOS, K. G. Estudo de extração de óleo vegetal com solvente em leito fixo empregando energia solar. In: XXXVIII Congresso Brasileiro de Sistemas Particulados, Maringá, 2017.

SILVA, L. R. C.; RIBEIRO, M. B. M.; OLIVEIRA, A. D.; SILVA, C. S.; FARIA, E. V.; SANTOS, K. G. Destilação solar do solvente etanol proveniente da extração de óleo de coco. Brazilian Journal of Development, v. 5, p. 28964-28982, 2019.

SOUZA, G. F. M. V. Secagem de sementes de soja em leito fixo: equilíbrio e cinética da sílica gel para controle de umidade, modelagem do processo e análise da qualidade das sementes. 2013. 157 p. Tese (Doutorado em Engenharia Mecânica) Universidade Federal de Uberlândia, Uberlândia, 2013.

TAVARES, F. P.; SILVÉRIO, B. C.; VIEIRA NETO, J. L.; SANTOS, K. G. Extração sustentável de óleo de pinhão manso com solvente aquecido por radiação solar. Brazilian Journal of Development, v. 5, p. 28909-28925, 2019.

TAVARES, F. P; SANTOS, K. G. Projeto e construção de um concentrador solar biangular de doze lados aplicado à extração sólido-líquido. In: Anais do VI Congresso Brasileiro de Energia Solar, Belo Horizonte, 2016.

TAVARES, S. R.; SOUSA, N. G. Sistema de aquecimento solar de água: simulação e análise. Revista Brasileira de Ciência, Tecnologia e Inovação, v. 4, n. 1, p. 15-31, 2019.

VETTER, R. E. Secador Solar der Madeira: Um Manual de Construção e Operação. Manaus: INPA/CPPF, 2006.

VIDIGAL, S. M.; SEDIYAMA, M. A. N.; PEDROSA, M. W.; SANTOS, M. R. Produtividade de cebola em cultivo orgânico utilizando composto à base de dejetos de suínos.

Horticultura Brasileira, v. 28, n. 2, p. 168-173, 2010. 